\title{
Silencing of synaptotagmin 13 inhibits tumor growth through suppressing proliferation and promoting apoptosis of colorectal cancer cells
}

\author{
$\mathrm{QIN} \mathrm{LI}^{1 *}$, SHUN ZHANG $^{2 *}$, MIAO HU${ }^{1}$, MING XU ${ }^{1}$ and XIAOHUA JIANG ${ }^{2}$ \\ Departments of ${ }^{1}$ Gastroenterology and ${ }^{2}$ Gastrointestinal Surgery, Shanghai East Hospital, \\ Tongji University, Shanghai 200123, P.R. China
}

Received November 5, 2018; Accepted September 23, 2019

DOI: $10.3892 /$ ijmm.2019.4412

\begin{abstract}
The treatment of colorectal cancer is currently hampered by the lack of early detection technology. The identification of molecular biomarkers for colorectal cancer is crucial for improving prognosis. Synaptotagmin (SYT) 13 has been reported to be associated with several human tumors, but its role in colorectal cancer remains elusive. In the present study, immunohistochemistry was utilized to detect the expression of SYT13 in colorectal cancer tissues and cells. MTT, colony formation, wound healing and Transwell assays were conducted to evaluate the effect of SYT13 knockdown on the biological behavior of RKO and HCT116 cells. Cell apoptosis and cell cycle profiles were detected by FACS. A mouse xenograft model was constructed to investigate the effect of SYT13 on colorectal cancer in vivo. The results indicated that SYT13 was upregulated in colorectal tumor tissues compared with paracancerous tissues. Silencing of SYT13 inhibited the proliferation, colony formation, migration and invasion ability of RKO and HCT116 cells. Moreover, SYT13 knockdown arrested the cell cycle in the G2 phase, thus inducing cell apoptosis. The in vivo experiments also demonstrated the inhibitory effect of SYT13 on tumor growth. In conclusion, the present study demonstrated that SYT13 may act as a promoter in the development and progression of colorectal cancer and,
\end{abstract}

Correspondence to: Dr Ming Xu, Department of Gastroenterology, Shanghai East Hospital, Tongji University, 1800 Yuntai Road, Pudong, Shanghai 200123, P.R. China

E-mail:xm73dr@gmail.com

Dr Xiaohua Jiang, Department of Gastrointestinal Surgery, Shanghai East Hospital, Tongji University, 1800 Yuntai Road, Pudong, Shanghai 200123, P.R. China

E-mail: 13916708025@163.com

"Contributed equally

Key words: colorectal cancer, synaptotagmin 13, knockdown, cell proliferation, cell apoptosis therefore, may be of value as a target for the development of novel treatment strategies.

\section{Introduction}

Colorectal cancer is the third most frequently diagnosed type of cancer in humans and is a major cause of cancer-related mortality worldwide (1). Despite the considerable progress in colorectal cancer treatment, its mortality rate remains high and the prognosis remains poor due to the lack of early diagnostic techniques and efficient therapies (2). The majority of colorectal cancers start as benign polyps and are not associated with distinct symptoms until the tumor reaches an advanced stage $(3,4)$. Therefore, the early detection of colorectal cancer or benign polyp is crucial for improving the prognosis or even preventing the occurrence of colorectal cancer. The occurrence of colorectal cancer is a complex multistep process involving multiple genes: Some genetic mutations may be present in the colorectal epithelial cells at birth, but most mutations result from the effects of acquired environmental factors or DNA replication mismatches (5). The process includes changes from normal epithelium to abnormal hyperplasia, adenoma, cancerization and cancer metastasis, and a series of mutations, mismatches, activation of oncogenes and identification of tumor suppressor genes occur during this process (6). Although some molecular biomarkers for the early detection of the incidence and development of colorectal cancer have been identified, their clinical application is currently limited $(7,8)$. Therefore, there is an urgent need to identify novel biomarkers for colorectal cancer and its prognosis.

Synaptotagmins (SYTs) are a family of membraneassociated synaptic vesicle transport proteins that largely serve as $\mathrm{Ca}^{2+}$ sensors in vesicular trafficking and exocytosis $(9,10)$. SYTs are characterized by a short extracellular N-terminal, a transmembrane domain, two tandem $\mathrm{C} 2$ domains and a short C-terminal region $(11,12)$. SYTs are found primarily in tissues that possess regulatory secretory pathways. At least 16 isoforms of SYTs have been identified according to biochemical and phylogenetic analyses $(9,13)$. SYT13 is an atypical member of the SYT family (14). The most conserved function across the protein family appears to be $\mathrm{Ca}^{2+}$-independent binding to target SNARE heterodimers during membrane fusion, while 
SYT13 is one of the only two SYTs (including SYT12) that cannot bind to this complex $(15,16)$. Additionally, SYT13 lacks the $\mathrm{Ca}^{2+}$-dependent phospholipid-binding properties conserved in several of the family members (16). However, the function of SYT13, particularly the association between SYT13 and human cancers, remains largely unknown and is rarely reported. Grønborg et al reported reduced expression of SYT13 in a genome-wide analysis of pancreatic ductal adenocarcinoma compared with normal cells (17). Moreover, Jahn et al reported that human SYT13 acts as a liver tumor suppressor gene by complementing the molecular defect in GN6TF rat liver tumor cells to achieve normalized cellular phenotype and suppression of tumorigenicity (18).

Despite these results, however, research on the association between SYT13 and colorectal cancer is lacking. Therefore, the aim of the present study was to investigate the role of SYT13 in the development and progression of colorectal cancer. Immunohistochemical (IHC) staining was used to detect the difference in expression of SYT13 between colorectal cancer tissues and paracancerous tissues. SYT13 knockdown cell lines were constructed through infection of shSYT13 lentivirus plasmid and verified by western blot analysis and reverse transcription-quantitative PCR (RT-qPCR). MTT, colony formation, wound healing and Transwell assays were used to evaluate the effect of SYT13 knockdown on the biological behaviors of RKO and HCT116 cells. Cell apoptosis and cell cycle profiles were detected by fluorescence-activated cell sorting (FACS) to investigate the association between SYT13 knockdown and cell apoptosis. Finally, a mouse xenograft model was constructed to further verify the role of SYT13 in colorectal cancer.

\section{Materials and methods}

Target shRNA sequence design, shRNA lentiviral vector construction and cell infection. The human colorectal cancer cell lines RKO, HCT116, HT-29 and Caco2 were purchased from BeNa Culture Collection and cultured with DMEM (Corning Inc.) supplemented with $10 \%$ FBS (Invitrogen; Thermo Fisher Scientific, Inc.) at $37^{\circ} \mathrm{C}$ with $5 \% \mathrm{CO}_{2}$. The medium was changed every $72 \mathrm{~h}$.

Short hairpin RNAs (shRNAs) targeting SYT13-RNAi sequences (shSYT13-1: 5'-ATGTCTCTGTCAAGGTGA CCT-3', shSYT13-2: 5'-ACCTCCACTCTAACCAGTCCA-3', shSYT13-3: 5'-CCTGGACTATGACTGTCAGAA-3') were designed and synthesized (Generay Biotech Co. Ltd.). The shRNA was then cloned into lentiviral vector [with green fluorescent protein (GFP), Shanghai Biosciences] to form recombinant lentiviral shRNA expression vector. ShRNA-expressing lentiviruses were packaged and amplified by PCR and lentivirus plasmids were purified using ultracentrifugation. RKO, HCT116 cell suspensions were formed by trypsinization. Suspensions were cultured in six-well plates at 50,000 cells per well and incubated at $37^{\circ} \mathrm{C}, 5 \% \mathrm{CO}_{2}$ for $24 \mathrm{~h}$. Subsequently, the suspensions were infected with shRNA-containing lentiviruses and, $24 \mathrm{~h}$ later, the culture medium was replaced. The cells were cultured for a further $48 \mathrm{~h}$, and the fluorescence of GFP was observed under a fluorescence microscope to ensure that $>80 \%$ cells were infected.
Immunohistochemical (IHC) staining. Paraffin-embedded human colorectal cancer and adjacent tissue microarray (TMA) was purchased from Shanghai Outdo Biotech Co., Ltd. (HCoA180Su15-M). All patients provided written informed consent prior to sample collection. The sections were deparaffinized. After citrate antigen repair and blocking, the samples were incubated with the anti-SYT13 antibody $(1 ; 100$, Abcam, cat. no. ab110520) at $4^{\circ} \mathrm{C}$ overnight in an incubator. Tissue sections were stained with DAB, and again stained with hematoxylin. Images were captured using a photomicroscope (Olympus Corporation) and analyzed. Anti-Ki-67 antibody was purchased from Abcam (1:200, cat. no. ab16667) and used in IHC analysis of xenograft tumors.

RNA extraction and RT- $q P C R$. Target gene shSYT13 expression levels were measured by RT-qPCR. Briefly, TRIzol reagent (Invitrogen; Thermo Fisher Scientific, Inc.) was used to extract the RNA according to the manufacturer's instructions. Reverse Transcription kit (Takara) was used to synthesize cDNAs. The qPCR was carried out using Power SYBR-Green (Takara). GAPDH was used as an internal control. The PCR cycling conditions were as follows: Initial denaturation at $95^{\circ} \mathrm{C}$ for $30 \mathrm{sec}$, followed by 45 cycles at $95^{\circ} \mathrm{C}$ for $5 \mathrm{sec}, 60^{\circ} \mathrm{C}$ for $30 \mathrm{sec}, 95^{\circ} \mathrm{C}$ for $15 \mathrm{sec}, 55^{\circ} \mathrm{C}$ for $30 \mathrm{sec}$ and $95^{\circ} \mathrm{C}$ for $15 \mathrm{sec}$. RT-qPCR and data collection were carried out. Nanodrop 2000/2000C spectrophotometers (Thermo Fisher Scientific, Inc.) were used to analyze the relative levels of mRNAs and the quality of extracted RNA.

The primers used in qPCR were as follows: SYT13 forward: 5'-CCAAGGGAGTGTGGCCAATA-3' and reverse: 5'-CACAGATGTCCCGTCCAGG-3'; and GAPDH forward: 5'-TGACTTCAACAGCGACACCCA-3' and reverse: 5'-CAC CCTGTTGCTGTAGCCAAA-3'.

Western blot analysis. Cells were collected and lysed by using RIPA lysis buffer (Cell Signaling Technology, Inc.) including protease inhibitors on ice according to the manufacturer's instruction. The extracted protein was quantified by the BCA Protein Assay kit (Pierce; Thermo Fisher Scientific, Inc., cat. no. 23225). Then, the total protein was subjected to SDS-PAGE (10\%) for western blot analysis (20 $\mu \mathrm{g}$ per lane). After transferring to polyvinylidene difluoride (PVDF) membranes, blots were incubated with 5\% BSA in Tris-buffered saline containing $0.5 \%$ Tween-20 for $60 \mathrm{~min}$ and incubated overnight at $4^{\circ} \mathrm{C}$ on a rocker with the following primary antibodies: SYT13 (1:1,000, Abcam, cat. no. ab110520), N-cadherin (1:1,000; Abcam, cat. no. ab18203), vimentin (1:2,000; Abcam, cat. no. ab92547), Snail (1:1,000; Cell Signaling Technology, Inc., cat. no. 3879S), Bad (1:1,000; Abcam, cat. no. ab32445), Bcl-2 (1:1,000; Abcam, cat. no.ab194583), P53 (1:1,000; Abcam, cat. no. ab26), Survivin (1:2,000; Abcam, cat. no. ab469) and GAPDH (1:3,000; Bioworld, cat. no. AP0063). After washing three times with TBST for $5 \mathrm{~min}$, the sections were incubated with horseradish peroxidase (HRP) conjugated goat anti-rabbit IgG polyclonal secondary antibody $(1: 3,000$; Beyotime Institute of Biotechnology, cat. no. A0208) at room temperature for $1 \mathrm{~h}$. An ECL Plus ${ }^{\mathrm{TM}}$ western blotting system kit (GE Healthcare) was operated for color developing.

MTT assay. Cell viability was assessed using an MTT assay. After the trypsinization of cells in the logarithmic 
growth phase in each experimental group, 2,000 cells/well were seeded into a 96-well (100 $\mu \mathrm{l} /$ well) plate (Corning Inc., cat. no. 3599) overnight. A total of $20 \mu 1$ MTT $(5 \mathrm{mg} / \mathrm{ml})$ (Genview, cat. no. JT343) was added to each well $4 \mathrm{~h}$ prior to culture termination. DMSO $(100 \mu \mathrm{l})$ was added to dissolve formazan crystals. Absorbance values at $490 \mathrm{~nm}$ were determined for each well using enzyme-connected immunodetector and the reference wavelength was $570 \mathrm{~nm}$. The absorbance is associated with the percentage of living cells. The cell viability ratio was calculated using optical density (OD) as follows: Cell viability $(\%)=\mathrm{OD}($ treated$) / \mathrm{OD}$ (control) $\mathrm{x} 100 \%$.

Celigo cell counting assay. RKO and HCT116 cells infected with shSYT13 or shCtrl were seeded into 96-well plates at a density of 1,000 cells/well. The cells were cultured in a $5 \% \mathrm{CO}_{2}$ incubator at $37^{\circ} \mathrm{C}$ for 1 day. Then cell images were captured using Celigo image cytometer (Nexcelom Bioscience) once per day for 5 days. The cell numbers were also quantified by using Celigo image cytometer.

Colony formation assay. Four days after RKO and HCT116 cells were infected, cells in the logarithmic growth phase were digested by trypsin, resuspended, counted and seeded in 6-well plates at 400-1,000 cells per well. The cells were incubated for 14 days to form colonies. Then, the cells were washed by PBS, fixed in paraformaldehyde for $1 \mathrm{~h}$, stained with Giemsa for $20 \mathrm{~min}$, washed three times by $\mathrm{ddH}_{2} \mathrm{O}$ and then photographed with a digital camera. The number of colonies ( $>50$ cells/colony) was counted under a fluorescence microscope (MicroPublisher 3.3RTV, Olympus Corporation).

Wound healing assay. RKO and HCT116 infected cells were spread at the bottom of 96-well plates. A linear wound was created by scraping with a $100-\mu 1$ pipette tip across the confluent cell layer. After washing the cells three times to remove detached cells and debris, serum-free medium was added into the 96-well plates and incubated under the usual culture conditions $\left(37^{\circ} \mathrm{C}, 5 \% \mathrm{CO}_{2}\right)$ for $48 \mathrm{~h}$. Wound closure photographs were captured using a light microscope (DFC500, Leica Microsystems $\mathrm{GmbH}$ ) at indicated time points and the outcomes were analyzed.

Transwell assay. Under aseptic conditions, Transwell assay was conducted by Polycarbonate Membrane Corning Transwell experimental kit (Corning Inc.) in an empty 24-well plate. For migration detection, 10,000 cells were cultured in the upper chambers with serum-free medium. For invasion detection, the same number of cells were cultured in the upper chambers of Matrigel-coated inserts with serum-free medium. A total of $600 \mu \mathrm{l}$ of medium supplemented with $30 \%$ FBS was added to the lower chamber as the chemoattractant. After cell culture for the indicated time, the medium and cells remaining on the upper chamber were removed. Cells that had migrated to the lower chamber were stained by Giemsa for $20 \mathrm{~min}$, washed several times, and images were captured during microscopic inspection (MicroPublisher 3.3RTV, Olympus Corporation) according to the manufacturer's instructions.

Apoptotic assay. Cell apoptosis was detected by using Annexin V Apoptosis Detection kit APC (88-8007-74,
eBioscience). Briefly, lentivirus-infected cells were seeded in 6-cm dishes and then the cells were digested by trypsin and resuspended, followed by the addition of $10 \mu \mathrm{l}$ Annexin V-APC for cell staining for $15 \mathrm{~min}$ in the dark. The percentage of apoptotic cells was measured using FACScan (Merck KGaA) to assess the apoptotic rate, and the results were analyzed. Notably, the green fluorescence of GFP on the lentivirus vector was detected simultaneously, ensuring that only cells successfully infected with lentivirus were detected in the apoptotic assay.

Detection of cell cycle by fluorescence-activated cell sorting (FACS). RKO and HCT116 cells were washed by D-Hanks, digested by trypsin and centrifuged at $320 \mathrm{xg}$ at $4^{\circ} \mathrm{C}$ for $5 \mathrm{~min}$ when cells had grown to $\sim 80 \%$ confluence after infection. Then, cells were washed twice with cold PBS, fixed with cold $70 \%$ ethanol for $1 \mathrm{~h}$, centrifuged at $320 \mathrm{x} \mathrm{g}$ at $4^{\circ} \mathrm{C}$ for $5 \mathrm{~min}$ to discard ethanol and then resuspended in PBS. Finally, the cells were stained by propidium iodide (PI) (Sigma-Aldrich; Merck KGaA, cat. no. P4170) (PI $2 \mathrm{mg} / \mathrm{ml}$, RNase $10 \mathrm{mg} / \mathrm{ml}$ and PBS) and a total of 10,000 fixed cells were analyzed by BD FACSCalibur flow cytometer (BD Biosciences) with the throughput of cells $\sim 200-350 \mathrm{cell} / \mathrm{sec}$.

Tumorigenesis in vivo. Animal experiments were approved by the Ethics Committee of Shanghai Tongji University and were carried out in accordance with the institutional guidelines for animal care and protection. A total of $10 \mathrm{BALB} / \mathrm{c}$ male nude mice (10-15 g, 6 weeks old) were purchased from Shanghai Jiesijie Experimental Animals Co., Ltd., housed under SPF conditions in the laboratory with a 12/12 day/night cycle and fed with a standard diet. RKO cells $\left(5 \times 10^{6}\right.$ per mouse) transduced with $\operatorname{shSYT13}(\mathrm{n}=5)$ or the negative control $(\mathrm{n}=5)$ were subcutaneously injected into BALB/c male nude mice. Tumor growth was monitored and the volume was measured (length $x$ height $x$ width) at 4,7,11, 14 and 17 days post-inoculation by a caliper. At 17 days after injection, the mice were euthanized by injecting $1 \%$ pentobarbital sodium (100 $\mathrm{mg} / \mathrm{kg}$ body weight) and xenograft tumors were weighed.

Statistical analysis. The data are expressed as mean \pm standard deviation $(\mathrm{n} \geq 3)$ and analyzed using GraphPad Prism 6 software (GraphPad Software, Inc.). The results of qPCR were analyzed by the $2^{-\Delta \Delta \mathrm{Cq}}$ method (19) and the $\Delta \mathrm{Cq}$ method was used in background expression detection. Chi-squared test was used for categorical variables. Continuous variables were compared with Student's t-test (two groups). One-way ANOVA followed by Bonferroni post hoc test was performed to evaluate the significance of the differences among 3 or more groups. P-values $<0.05$ were considered to indicate statistically significant differences.

\section{Results}

High expression of SYT13 in tumor tissues and construction of SYT13 knockdown RKO and HCT116 cell lines. First, IHC analysis was applied to investigate whether SYT13 is differentially expressed between colorectal tumor tissues and paracancerous tissues. As shown in Fig. 1A, the IHC results demonstrated distinctly higher expression of SYT13 in tumor 
A

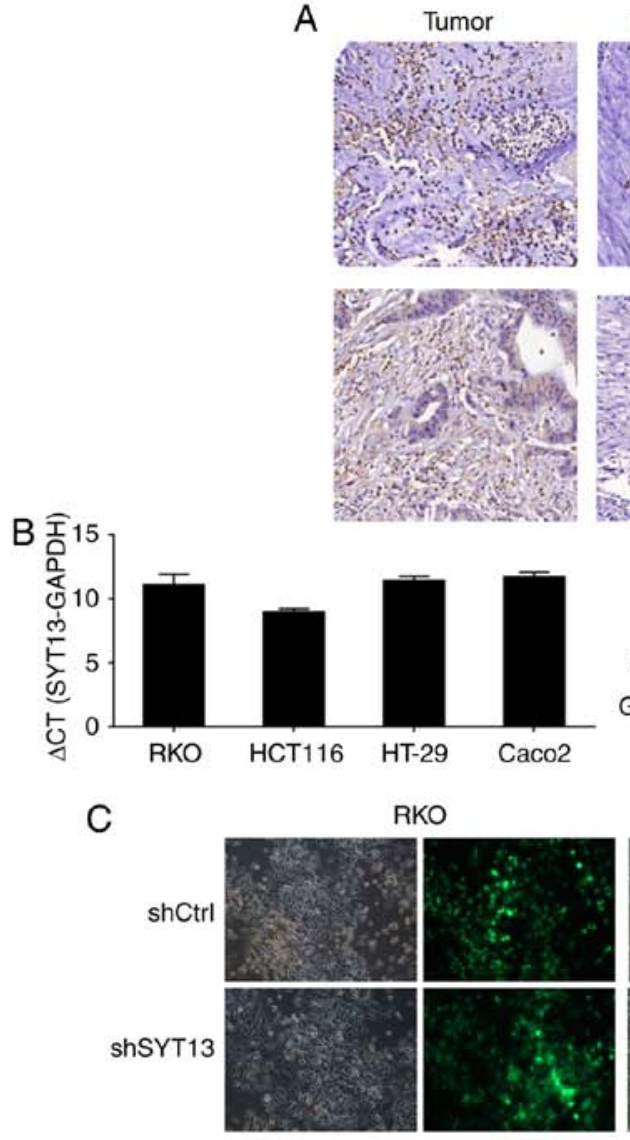

Paracancerous
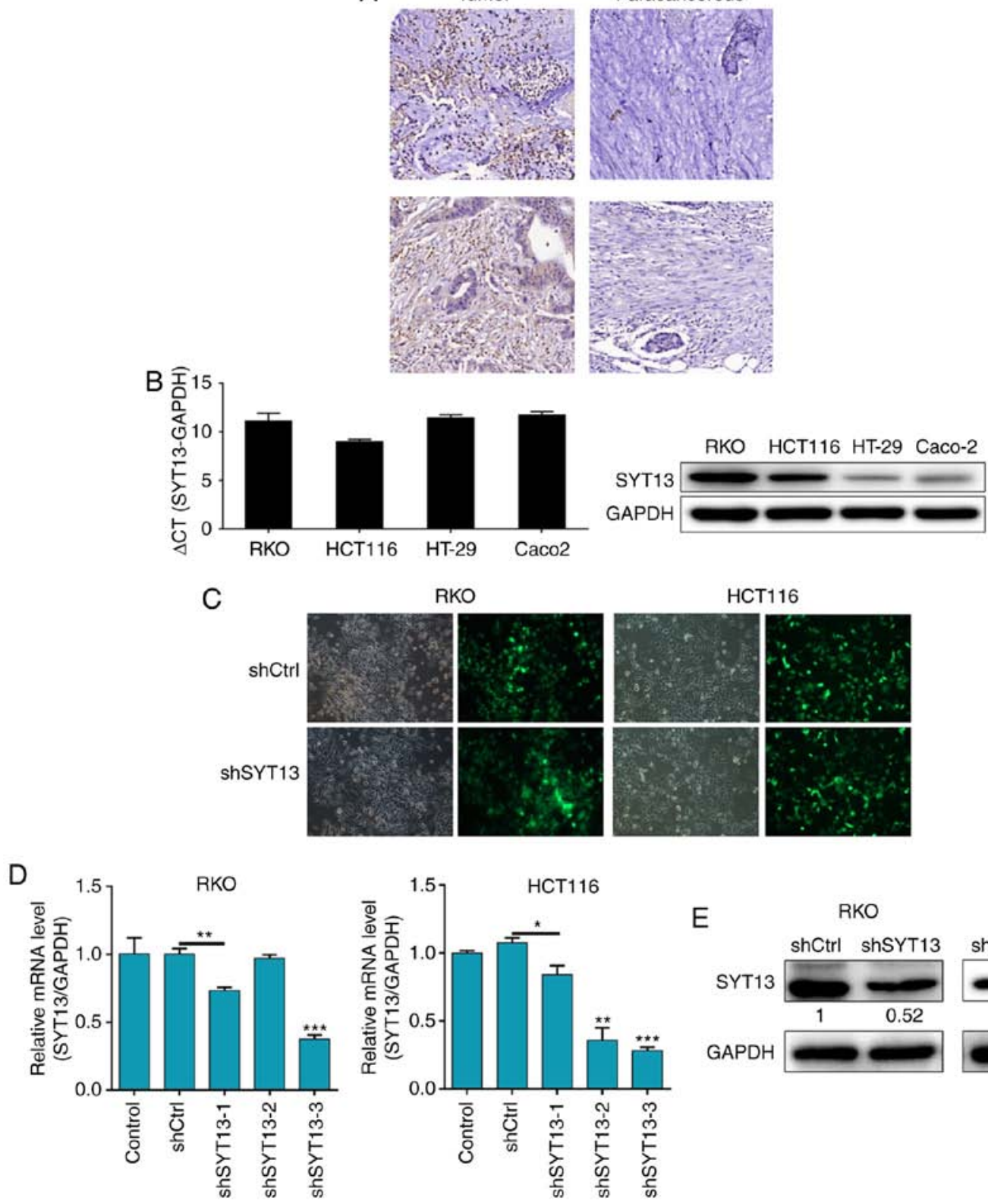

$\mathrm{E}$

HCT116

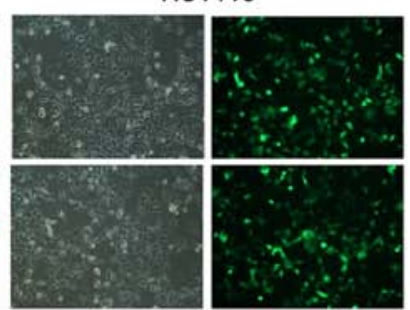

Figure 1. High expression of SYT13 in tumor tissues and construction of SYT13 knockdown cell models. (A) The expression levels of SYT13 in colorectal tumor tissues and paracancerous tissues were detected by immunohistochemical staining (magnification, x200). (B) The background expression of SYT13 in human colorectal cancer cell lines, including RKO, HCT116, HT-29 and Caco2, was detected by qPCR and western blot analyses, respectively. (C) The infection efficiencies for both cell lines were evaluated by the expression of green fluorescent protein at $72 \mathrm{~h}$ post-infection (magnification, x200). (D and E) The validity and efficiency of SYT13 knockdown were evaluated by (D) RT-qPCR and (E) western blot analysis. Data are presented as the mean \pm standard deviation ( $\mathrm{n} \geq 3) .{ }^{*} \mathrm{P}<0.05,{ }^{* *} \mathrm{P}<0.01,{ }^{* * *} \mathrm{P}<0.001$. SYT, synaptotagmin; RT-qPCR, reverse transcription-quantitative polymerase chain reaction.

tissues compared with that in paracancerous tissues. The percentage of high SYT13 expression was $80 \%$ in colorectal cancer tissues and $48 \%$ in adjacent non-cancerous tissues $(\mathrm{P}<0.001$; Table I). Moreover, the background expression of SYT13 in human colorectal cancer cell lines, including RKO, HCT116, HT-29 and Caco2, was detected by qPCR and western blot analysis and revealed relatively high expression of SYT13 in RKO and HCT116 cells (Fig. 1B). Therefore, the RKO and HCT116 cell lines were selected as the cell model and infected with the artificially prepared shSYT13 lentivirus plasmid, which was tagged by GFP, for SYT13 knockdown. The infection efficiency was evaluated through observation and analysis of the GFP expression at $72 \mathrm{~h}$ post-infection in the cells, with $>80 \%$ knockdown efficiencies for both cell lines proving successful infection (Fig. 1C). Subsequently, RNAi sequence screening was performed by RT-qPCR and verified by western blot analysis, demonstrating the efficacy of SYT13 knockdown by shSYT13-3 (Fig. 1D and E), which was used in all the subsequent experiments. The results demonstrated that, compared with the negative control, the protein levels of SYT13 in both cell lines were obviously suppressed and the mRNA levels of SYT13 in RKO and HCT116 cells were downregulated by 62.7 and $65.5 \%$, respectively (both $\mathrm{P}<0.05$ ). Therefore, based on the high expression of SYT13 in colorectal cancer, cell models of SYT13 knockdown were successfully established. 
Table I. Expression patterns of SYT13 in colorectal cancer tissues and paracancerous tissues as determined by immunohistochemical analysis.

\begin{tabular}{|c|c|c|c|c|}
\hline \multirow[b]{2}{*}{ SYT13 expression } & \multicolumn{2}{|c|}{ Tumor tissues } & \multicolumn{2}{|c|}{ Paracancerous tissues } \\
\hline & Cases, $\mathrm{n}$ & Percentage, $\%$ & Cases, $\mathrm{n}$ & Percentage, $\%$ \\
\hline Low & 10 & 20 & 26 & 52 \\
\hline High & 40 & 80 & 24 & 48 \\
\hline
\end{tabular}

All $\mathrm{P}<0.001$. SYT, synaptotagmin.

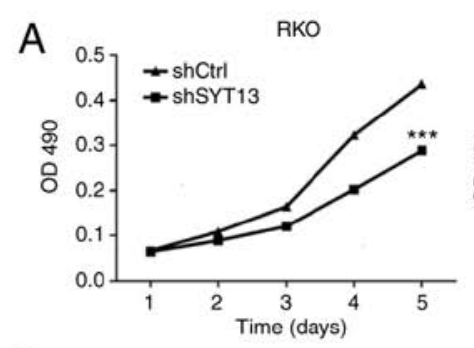

C

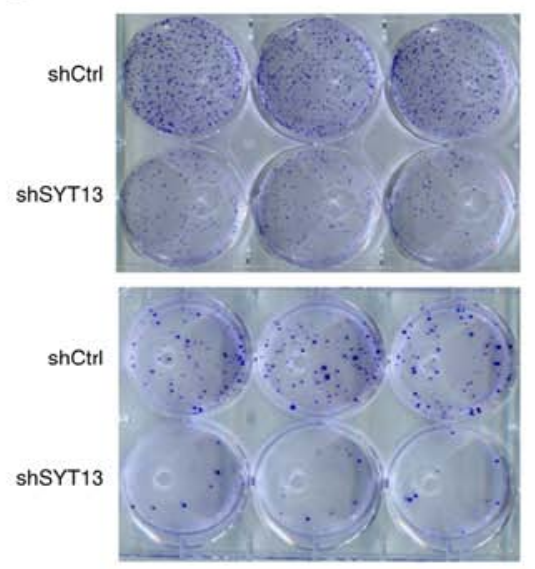

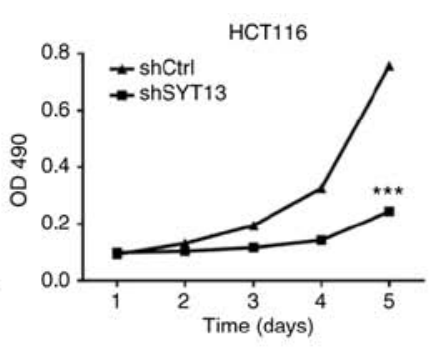
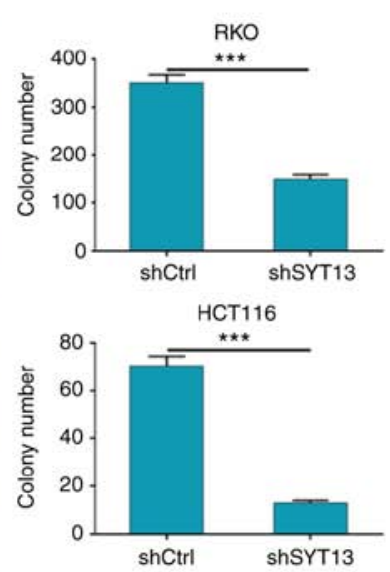

B
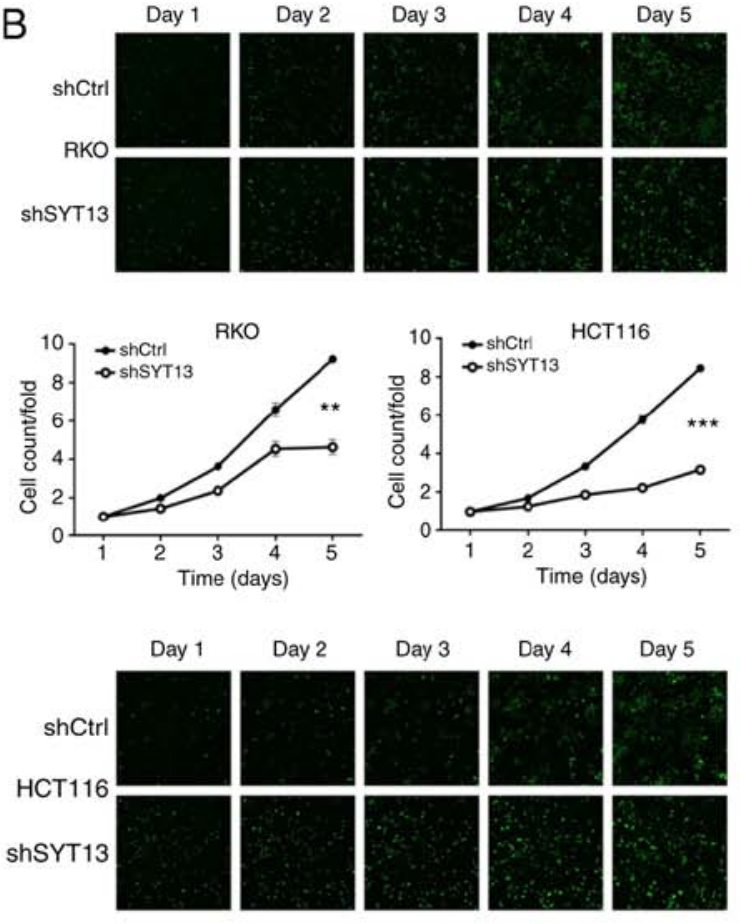

Figure 2. Knockdown of SYT13 inhibits cell proliferation. (A) MTT assay was used to evaluate the proliferation of RKO and HCT116 cells with SYT13 knockdown compared with negative control. (B) Celigo cell counting assay was performed to detect the effect of SYT13 knockdown on the proliferation of RKO and HCT116 cells. (C) Images of the colony numbers of RKO and HCT116 cells with or without SYT13 knockdown were captured to examine colony formation ability after 14 days of growth. Data are presented as the mean \pm standard deviation $(n \geq 3) .{ }^{* *} \mathrm{P}<0.01,{ }^{* * *} \mathrm{P}<0.001$. SYT, synaptotagmin.

Knockdown of SYT13 inhibits the proliferation, migration and invasion of RKO and HCT116 cells. Since the involvement of SYT13 in colorectal cancer has been suggested by its relatively high expression in tumor tissues, the role of SYT13 in biological cell behavior was subsequently investigated. As shown in Fig. 2A and B, RKO and HCT116 cells with SYT13 knockdown were subjected to MTT assay and Celigo cell counting assay to evaluate the cell proliferation, which revealed that knockdown of SYT13 significantly inhibited the proliferation of RKO and HCT116 cells compared with the negative control. Moreover, the long-term effect of SYT13 knockdown on cell proliferation was studied by colony formation assay, allowing cells with or without SYT13 knockdown to grow for 14 days. As shown in Fig. 2C, the number of colonies, as well as the colony formation ability of both cell lines, was significantly inhibited by the knockdown of SYT13, which was consistent with the results of the MTT assay. In addition, the wound healing and Transwell assays were used to estimate the migration ability of RKO and HCT116 cells with SYT13 knockdown compared with the negative control. As shown in Fig. 3A and B, the results obtained from both assays proved that the migration ability of cancer cells was drastically inhibited by the knockdown of SYT13. Moreover, cell invasion ability was assessed by Transwell assay, which also indicated suppressed invasion ability of RKO and HCT116 cells in the shSYT13 group (Fig. 3C). Furthermore, the results of the detection of epithelial-to-mesenchymal transition (EMT)-related proteins, including $\mathrm{N}$-cadherin, vimentin and Snail, by western blotting were also consistent with the results of the wound healing and Transwell assays (Fig. 3D). Taken together, these results demonstrated the possible involvement of SYT13 in the development and progression of colorectal cancer. 
A

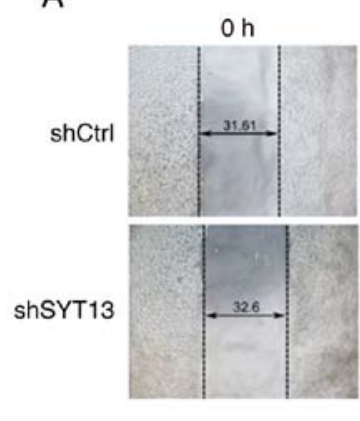

$\mathrm{Oh}$

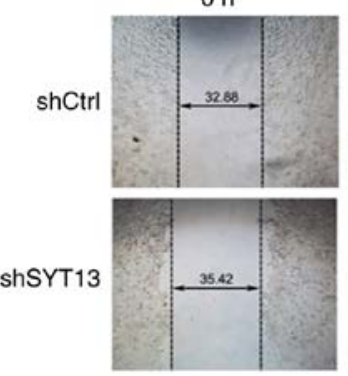

B
$24 \mathrm{~h}$

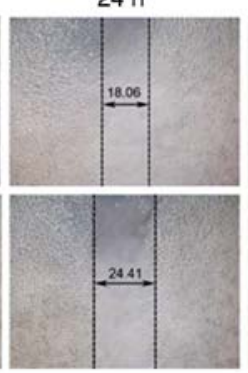

HCT116
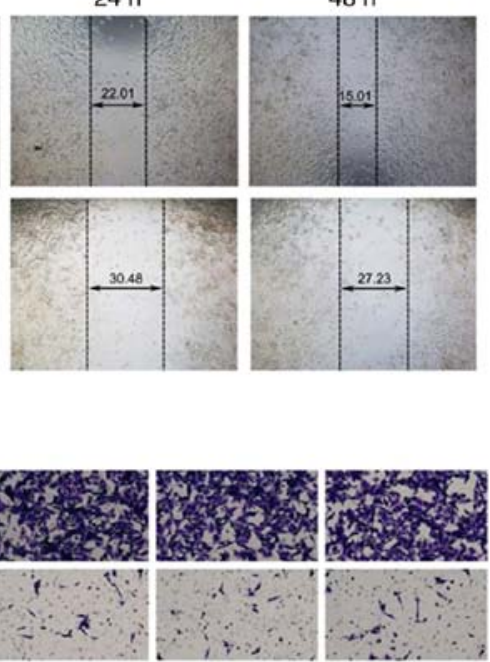

$36 \mathrm{~h}$

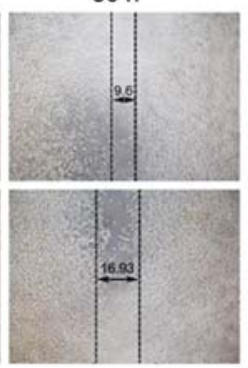

$48 \mathrm{~h}$

\section{西}
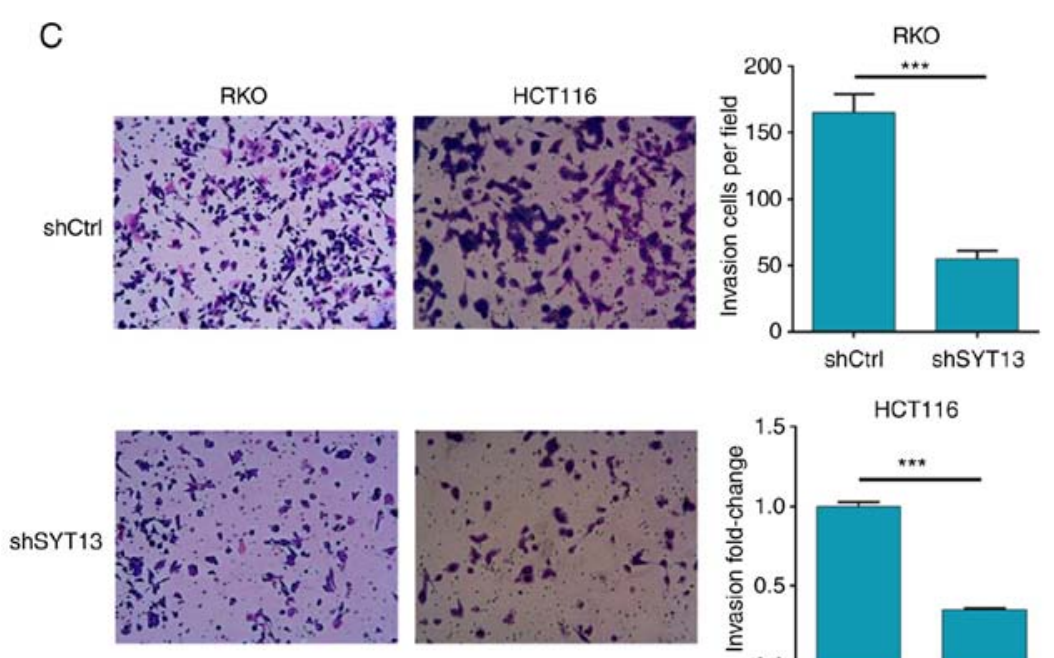
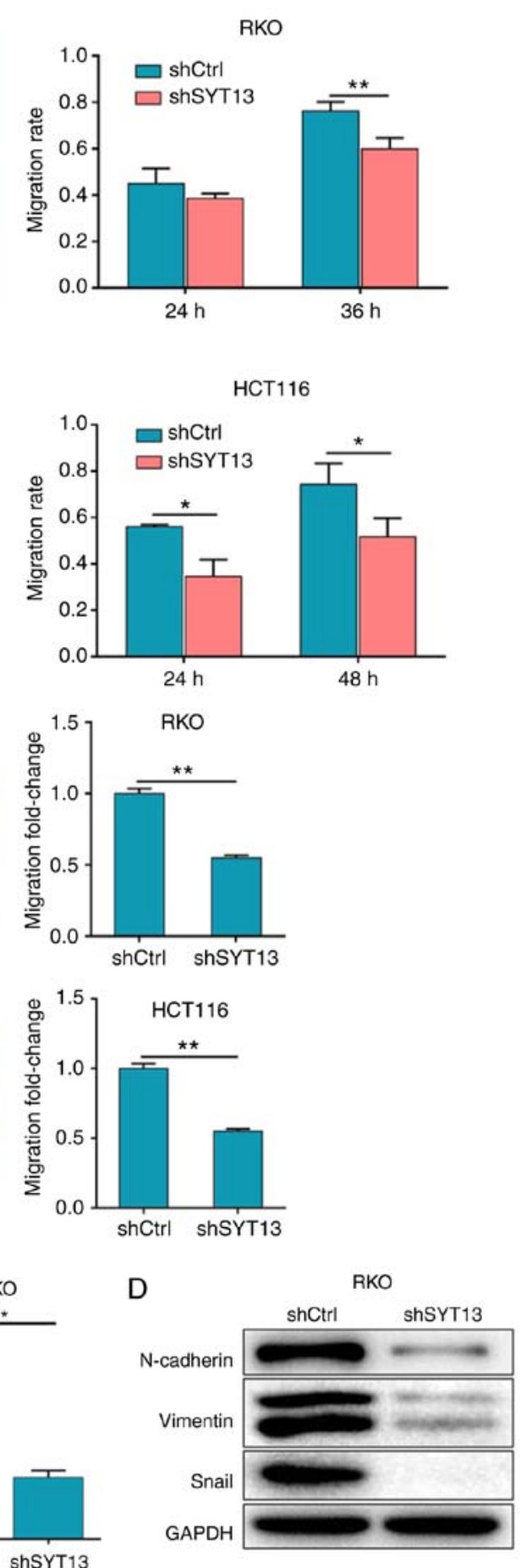

HCT116

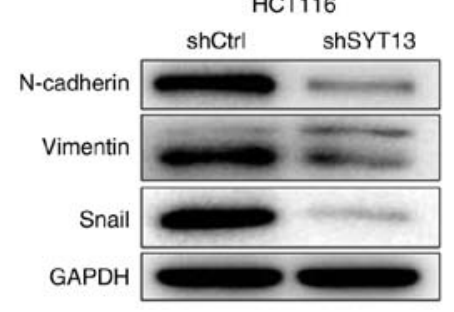

Figure 3. Knockdown of SYT13 inhibits cell migration and invasion. (A) Wound healing assay was used to determine the migration ability of RKO and HCT116 cells with SYT13 knockdown compared with the negative control. Representative images were selected from 3 independent experiments. (B and C) Transwell assay was performed to evaluate the (B) migration and (C) invasion ability of RKO and HCT116 cells with SYT13 knockdown compared with the negative control. Representative images were selected from 3 independent experiments. (D) The expression levels of EMT-related proteins, including N-cadherin, vimentin and Snail, in cells with or without SYT13 knockdown were detected by western blot analysis. Data are presented as the mean \pm standard deviation (n $\geq 3) .{ }^{*} \mathrm{P}<0.05,{ }^{* *} \mathrm{P}<0.01,{ }^{* * *} \mathrm{P}<0.001$. SYT, synaptotagmin; EMT, epithelial-to-mesenchymal transition. 

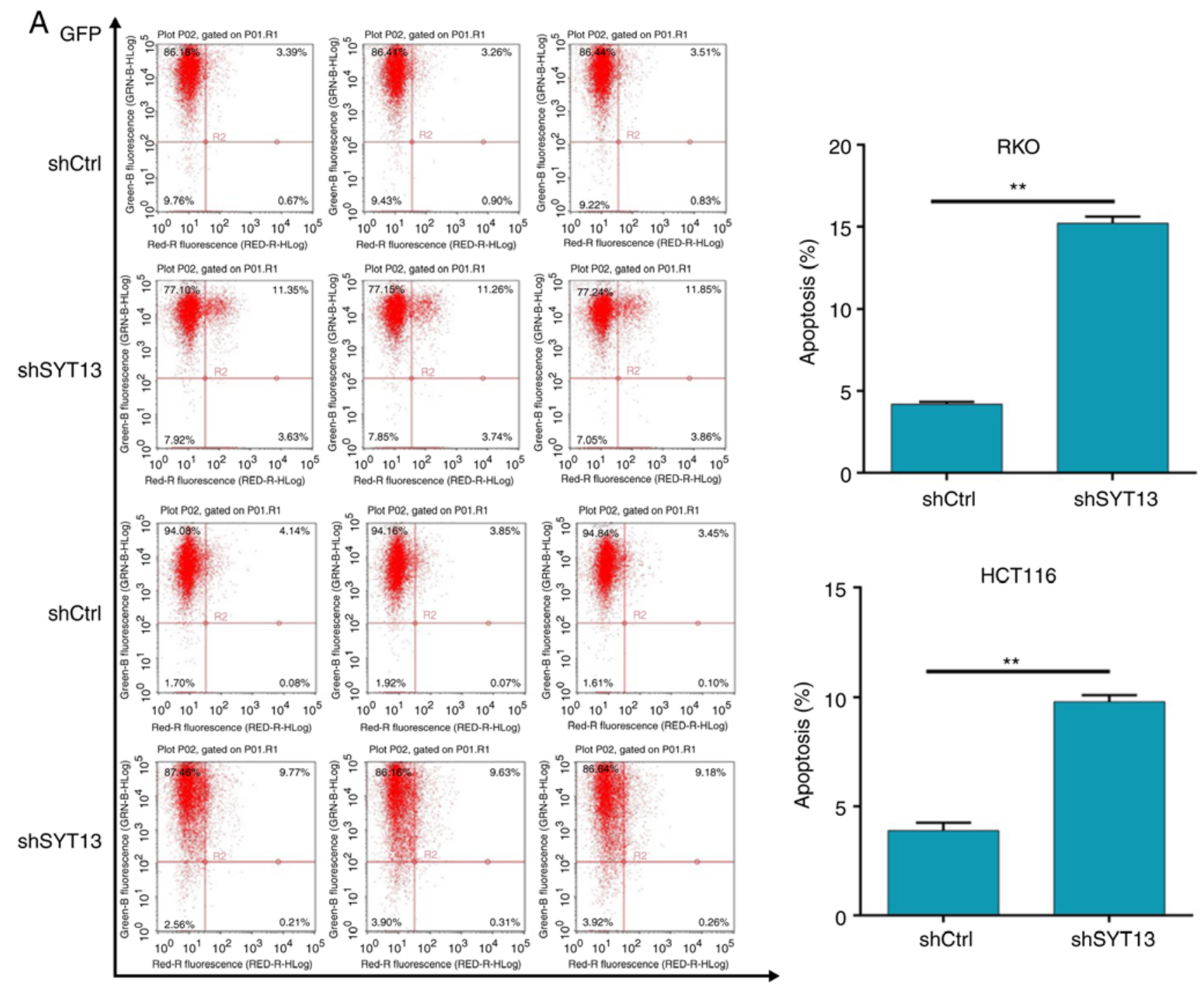

Figure 4. Knockdown of SYT13 induces cell apoptosis. (A) Flow cytometry analysis was employed to detect the percentage of apoptotic cells among RKO and HCT116 cells with SYT13 knockdown compared with the negative control. Data are presented as the mean \pm standard deviation (n $\geq 3)$. ${ }^{* *} \mathrm{P}<0.01$. SYT, synaptotagmin.

Knockdown of SYT13 induces apoptosis of RKO and HCT116 cells. In order to further investigate the effect of SYT13 knockdown on cell apoptosis, flow cytometry analysis was utilized to detect the apoptosis percentage. As shown in Fig. 4A, the knockdown of SYT13 induced an apoptosis ratio of RKO and HCT116 cells more than 2-fold higher compared with the negative control, indicating the ability of SYT13 knockdown to induce apoptosis in colorectal cancer cells. Furthermore, a comparison of the cell cycle profiles of RKO and HCT116 cells with SYT13 knockdown and the negative control (Fig. 4B) demonstrated that, compared with the negative control, the percentage of cells in the $\mathrm{G} 2$ phase was notably increased by SYT13 knockdown; a corresponding decrease in the percentage of cells in the $\mathrm{S}$ phase was observed simultaneously, indicating that cells were arrested in the G2 phase after SYT13 knockdown. Therefore, it may be concluded that SYT13 knockdown exerts an inhibitory effect on cell proliferation through arrest of the cells in the G1 phase of the cell cycle.
Knockdown of SYT13 impairs tumorigenesis in vivo. To confirm whether knockdown of SYT13 can impair tumor growth in vivo, a mouse xenograft model was constructed by subcutaneously injecting cancer cells into nude mice. After 17 days, the mice were euthanized and the tumors were weighed. The results demonstrated that tumor growth was distinctly slower in mice of the shSYT13 group compared with the shCtrl group (Fig. 5A and B). The weight of the tumors formed by SYT13 knockdown RKO cells was also significantly lower compared with that in the negative control group $(\mathrm{P}<0.001$, Fig. $5 \mathrm{~B}$ and $\mathrm{C})$. In addition to the difference in tumor size, we also observed that the tumors formed by shCtrl cells displayed a higher Ki-67 index compared with tumors formed by shSYT13 cells, as determined by IHC analysis (Fig. 5D). Finally, the expression of SYT13 in the resected tumors was also detected by qPCR and western blotting to confirm knockdown of SYT13 (Fig. 5E and F). Taken together, these results indicate that knockdown of SYT13 impairs tumorigenicity, which was 
B

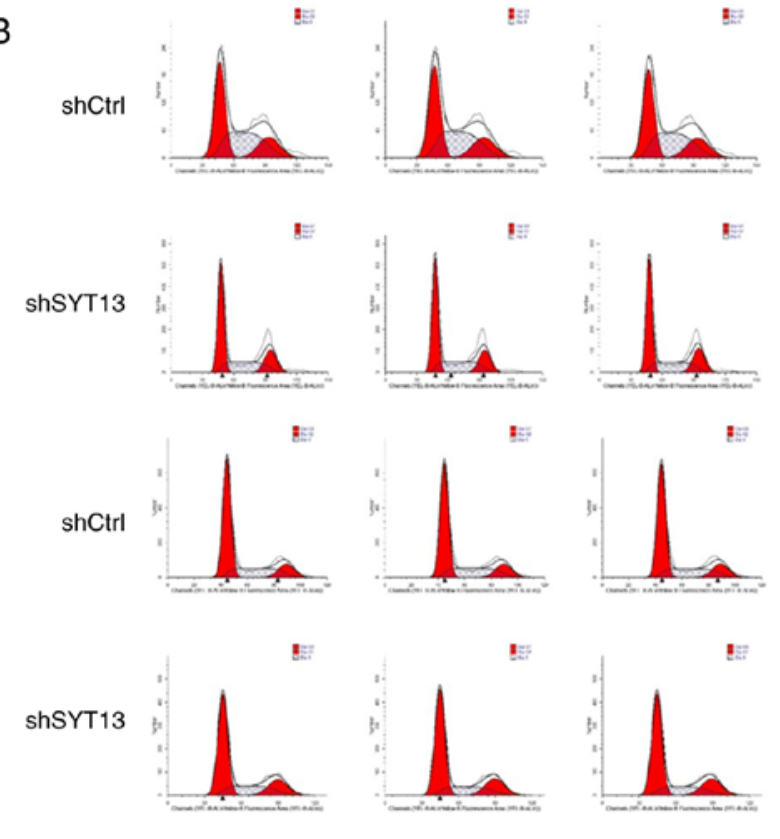

C

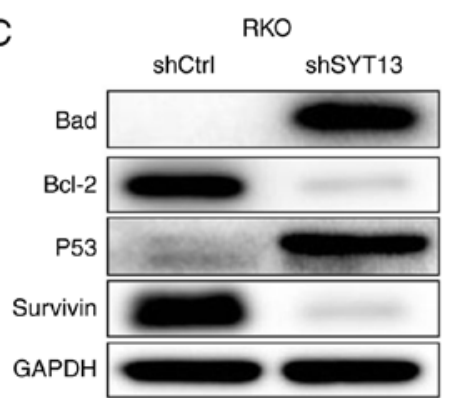

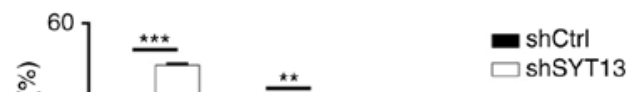
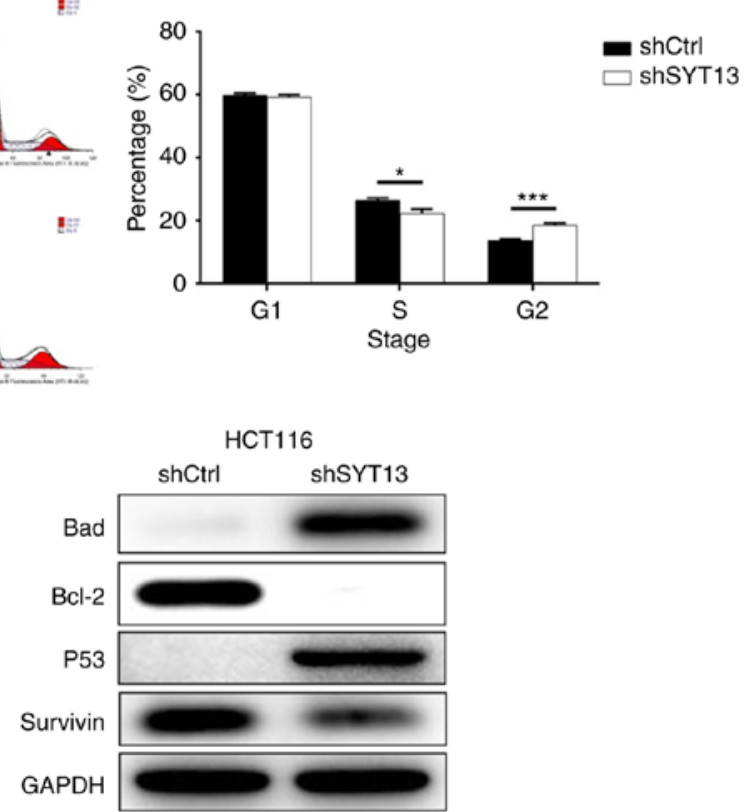

Figure 4. Continued. Knockdown of SYT13 induces cell apoptosis. (B) Cell cycle analysis of RKO and HCT116 cells with SYT13 knockdown and the negative control, and the percentage of cells in the G1, S and G2 phase of the cell cycle. (C) The expression levels of several apoptosis-related proteins, including Bad, Bcl-2, P53 and survivin, were detected by western blot analysis. Data are presented as the mean \pm standard deviation $(\mathrm{n} \geq 3) .{ }^{*} \mathrm{P}<0.05,{ }^{* *} \mathrm{P}<0.01,{ }^{* * * *} \mathrm{P}<0.001$. SYT, synaptotagmin.

consistent with the data obtained by the proliferation and apoptosis assays in vitro.

\section{Discussion}

Colorectal cancer is the third most commonly diagnosed cancer worldwide and one of the leading causes of cancer-related mortality. It has been estimated that, in 2012, 1.3 million new colorectal cancer cases were diagnosed and nearly 700,000 patients succumbed to the disease (20). Colorectal cancer is a polygenic disease, which is caused by genetic and epigenetic changes in oncogenes, tumor suppressor genes, mismatched repair genes, and cell cycle regulation genes in colonic mucosal cells (5). In order to achieve early detection, thereby improving prognosis and reducing mortality, scientists have been exploring and validating molecular markers as treatment targets. Gene mutation is a key factor in the incidence and development of colorectal cancer. It has been reported that the inactivation of adenomatous polyposis coli (APC) plays an important role in the early stages of colorectal cancer (21). The high expression and mutation of APC may be used as a prognostic indicator for the clinical outcomes of colorectal cancer (22). Similarly, vascular endothelial growth factor is also more highly expressed in colorectal cancer, which may provide valuable prognostic information (23). Although colonoscopy remains the standard screening test for colorectal cancer diagnosis, the assessment of microRNAs (miRNAs) in the plasma has opened up a new field in biomarker research (24). For example, miR-21, miR-106a, miR-135 and miR-1792 were found to be overexpressed in the serum of colorectal cancer patients. In addition, serum miR29a and miR-92a may provide practical information for the diagnosis of colorectal cancer patients $(25,26)$. Furthermore, various types of oncoproteins have been reported to be associated with the diagnosis and prognosis of colorectal cancer. Lin et al reported that the abnormal upregulation of the expression of insulin-like growth factor-II mRNA-binding protein 3 (IMP3) may promote lymph node metastasis, which is associated with poor prognosis and short survival time of colorectal cancer patients (27). Therefore, IMP3 may be a potential biomarker for evaluating the progression and prognosis of colorectal cancer (28).

SYTs are type III $\mathrm{Ca}^{2+}$-dependent membrane proteins characterized by tandem cytoplasmic repeats homologous to protein kinase C (29). Among the SYT family isoforms, SYT1-6 and 9-13 have been reported to be mainly expressed in brain tissue, while SYT5, 9 and 13 may also be detected in primary $\beta$-cells. On the other hand, SYT7, 8, 14 and 15 are 
A
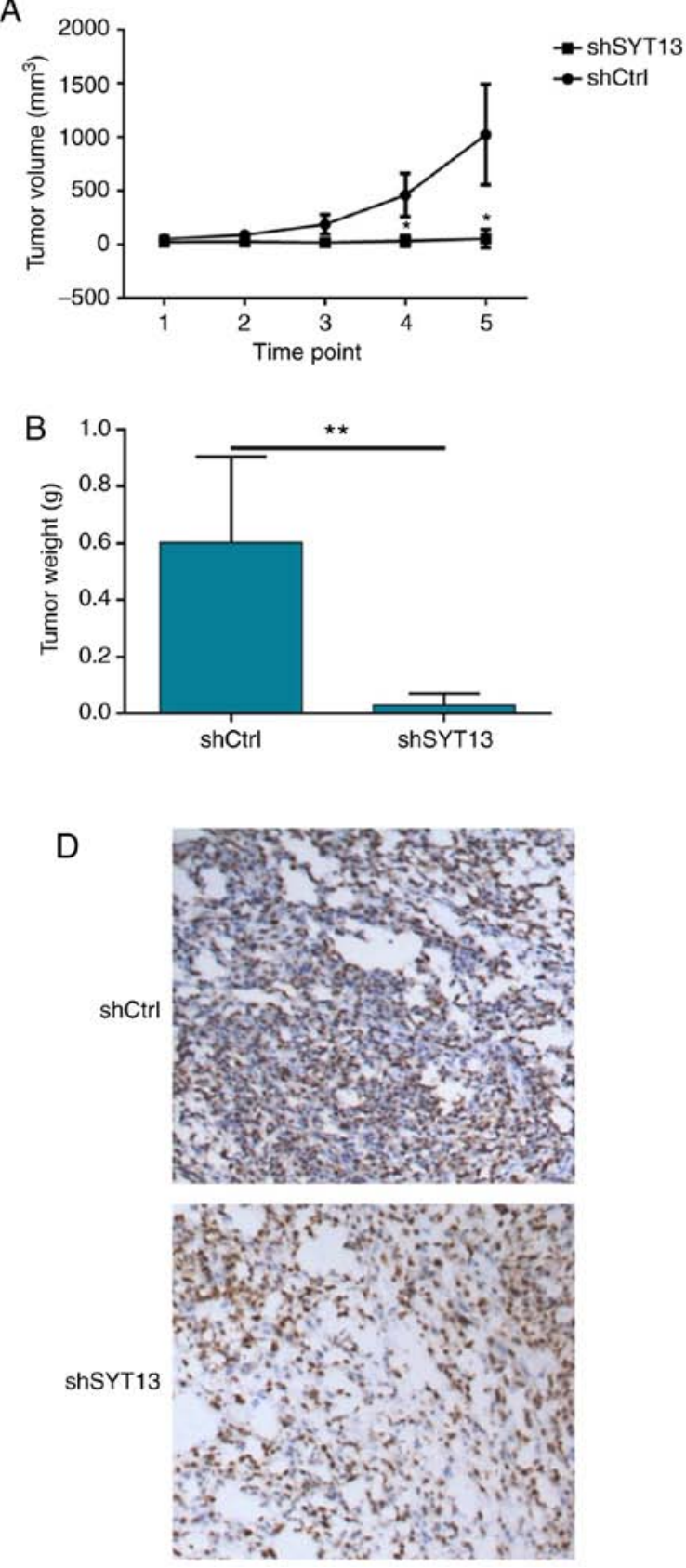

C

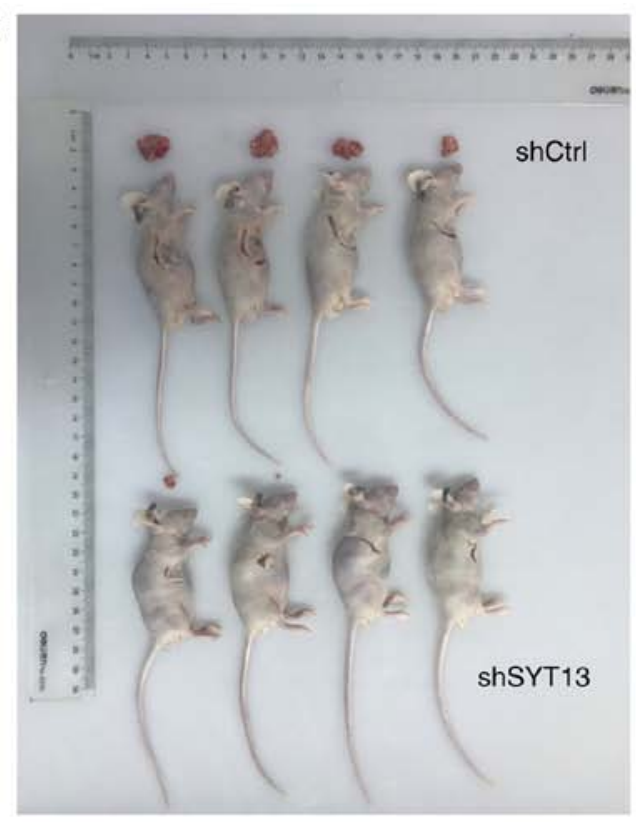

$\mathrm{E}$

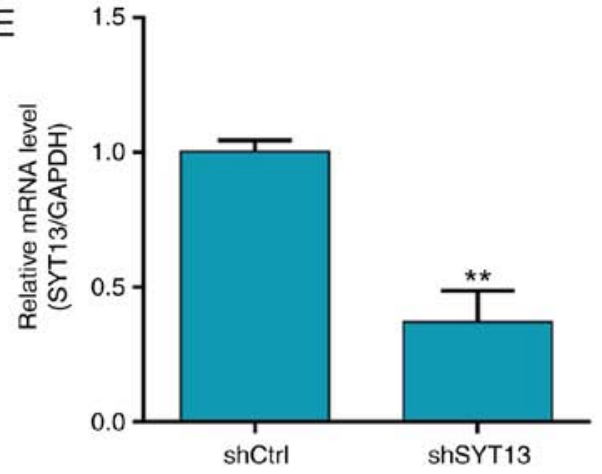

$\mathrm{F}$

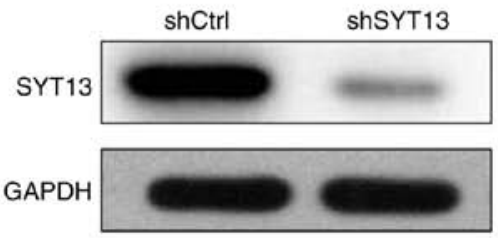

Figure 5. Knockdown of SYT13 inhibits tumor growth in a mouse xenograft model. (A) The volume of tumors in shCtrl and shSYT13 groups was measured at 4, 7, 11, 14 and 17 days post-injection. (B) Mean weight of the tumors in the shCtrl and shSYT13 groups. (C) Macroscopic observation of tumors resected from mice in the shCtrl and shSYT13 groups. (D) The tumor sections were subjected to immunohistochemical staining using an antibody against Ki-67 (magnification, $\mathrm{x} 200$ ). (E and F) The expression of SYT13 in the tumors was detected by (E) quantitative PCR analysis and (F) western blotting. Data are presented as the mean \pm standard deviation $(\mathrm{n} \geq 3) .{ }^{*} \mathrm{P}<0.05,{ }^{* *} \mathrm{P}<0.01$. SYT, synaptotagmin.

mainly expressed in the heart, kidney, and pancreas $(30,31)$. With the advances in research, the association between SYT and human diseases, particularly cancer, has been gradually uncovered. Andersson et al demonstrated that the reduced expression of exocytotic genes, including SYT4, 7, 11 and 13, contributes to impaired insulin secretion, indicating the possible involvement of these genes in the pathogenesis of type 2 diabetes (32). Moreover, Sreenath et al reported that the glutathione S-transferase-SYT complex, which may be observed in human breast tumors but not in adjacent non-cancerous tissues, possesses the potential to be a marker for breast cancer (33).
The human SYT13 gene is composed of 6 coding exons and 5 gt-ag introns distributed over $42 \mathrm{~kb}$ of genomic DNA (34). As an atypical member of the SYT family, SYT13 is highly expressed in the brain and lacks essential amino acid residues in the $\mathrm{C} 2$ terminal for $\mathrm{Ca}^{2+}$ binding and, thus, the accompanying $\mathrm{Ca}^{2+}$-dependent regulation of phospholipid-binding activity, which are important properties of several other isoforms (15). The function of SYT13 is largely unknown and only occasionally reported. Han et al indicated that contextual fear conditioning test could regulate the mRNA expression levels of SYT13 within various brain regions during both acquisition and retrieval sessions, suggesting the 
likely involvement of SYT13 in the process of contextual fear memory (35). Identification of the serial differential expression of genes from normal tissues to primary tumors to metastases indicated that various genes, including PMP22, SYT13 and SERPINA10, are associated with the progression of small bowel neuroendocrine tumors (36). Jahn et al demonstrated that the human SYT13 gene acts as a liver tumor suppressor gene and its function may be mediated through pathways implicated in mesenchymal-to-epithelial transition (37). Importantly, Zhu et al observed differential expression of SYT13 between left- and right-sided colon carcinomas by microarray analysis (38), suggesting the possible involvement of SYT13 in colorectal cancer. Therefore, the aim of the present study was to conduct a pioneer research on the association between SYT13 and the development and progression of colorectal cancer.

In the present study, the relatively upregulated expression of SYT13 in colorectal cancer tissues compared with paracancerous tissues was first evidenced by IHC. Based on these results, SYT13 knockdown cell lines were constructed through the infection of RKO and HCT116 cells with shSYT13 lentivirus plasmid. The efficiencies of infection and SYT13 knockdown were evaluated by observation of fluorescence intensity and western blot analysis combined with RT-qPCR, respectively, which demonstrated $>80 \%$ infection efficiency, and $62.7 \%(\mathrm{RKO}, \mathrm{P}<0.05)$ and $65.5 \%(\mathrm{HCT} 116, \mathrm{P}<0.05)$ knockdown efficiency. Subsequently, MTT and Celigo cell counting assays demonstrated a markedly slower proliferation rate of RKO and HCT116 cells with SYT13 knockdown compared with the negative control. Colony formation assay also revealed that distinctly fewer colonies were formed from cells with SYT13 knockdown compared with the negative control. Transwell assay demonstrated that knockdown of SYT13 reduced the migration and invasion ability of RKO and HCT116 cells compared with the negative control, which was consistent with the results of the wound healing assay. Although the IHC analysis of E-cadherin in colorectal cancer tissues failed to reveal the difference due to the non-sufficient signal strength, the detection of EMT-related proteins in RKO and HCT116 cells indicated the inhibition of EMT by SYT13 knockdown. Moreover, the significantly enhanced apoptosis of RKO and HCT116 cells induced by SYT13 knockdown were revealed by flow cytometric analysis and proven by detection of apoptosis-related proteins. The cell cycle profiles measured by FACS also proved that knockdown of SYT13 arrested RKO cells in the G2 phase. More importantly, the investigation of a mouse xenograft model demonstrated that the knockdown of SYT13 markedly inhibited the growth of the xenograft tumor compared with the negative control group, which was also consistent with the results of the cell experiments.

In conclusion, all the abovementioned results demonstrated that SYT13 may act as tumor promoter in colorectal cancer, and may serve as a future target for developing novel treatments for colorectal cancer. Further studies focusing on the regulatory mechanism of SYT13 may enable a better understanding of colorectal carcinogenesis.

\section{Acknowledgements}

Not applicable.

\section{Funding}

The present study was supported by the Shanghai Pudong New Area Science and Technology Development Fund Innovation Fund Project (grant no. PKJ2014-Y12) and the Top-Level Clinical Discipline Project of Shanghai Pudong (grant no. PWYgf2018-04).

\section{Availability of data and materials}

The datasets used and/or analyzed during the present study are available from the corresponding author on reasonable request.

\section{Authors' contributions}

MX and XJ conceived and designed the experiments. QL performed the experiments. SZ and $\mathrm{MH}$ conducted data analysis. QL wrote the manuscript. All authors read and approved the final manuscript.

\section{Ethics approval and consent to participate}

All animal experiments were approved by the Ethics Committee of Shanghai Tongji University and were carried out in accordance with the institutional guidelines for animal care and protection.

\section{Patient consent for publication}

Not applicable.

\section{Competing interests}

The authors declare that they have no competing interests.

\section{References}

1. Haggar FA and Boushey RP: Colorectal cancer epidemiology: Incidence, mortality, survival, and risk factors. Clin Colon Rectal Surg 22: 191-197, 2009.

2. Lao VV and Grady WM: Epigenetics and colorectal cancer. Nat Rev Gastro Hepat 8: 686-700, 2011.

3. Martenson JA, Haddock MG and Gunderson LL: Cancers of the Colon, Rectum, and Anus. Springer Berlin Heidelberg 34: 545-559, 2006

4. Weitz J, Koch M, Debus J, Höhler T, Galle PR and Büchler MW: Colorectal cancer. Lancet 365: 153-165, 2005.

5. Migliore L, Migheli F, Spisni R and Coppedè F: Genetics, cytogenetics, and epigenetics of colorectal cancer. J Biomed Biotechnol 2011: 792362, 2011.

6. Pox CP: Controversies in colorectal cancer screening. Digestion 89: 274-281, 2014.

7. Lieu C and Kopetz S: The SRC family of protein tyrosine kinases: A new and promising target for colorectal cancer therapy. Clin Colorectal Cancer 9: 89-94, 2010.

8. Lin JS, Piper MA, Perdue LA, Rutter CM, Webber EM, O'Connor E, Smith N and Whitlock EP: Screening for colorectal cancer: Updated evidence report and systematic review for the US preventive services task force. JAMA 315: 2576-2594, 2016.

9. Pang ZP and Südhof TC: Cell biology of $\mathrm{Ca}^{+}{ }^{+}$-triggered exocytosis. Curr Opin Cell Biol 22: 496-505, 2010.

10. Fernández-Chacón R, Königstorfer A, Gerber SH, García J, Matos MF, Stevens CF, Brose N, Rizo J, Rosenmund C and Südhof TC: Synaptotagmin I functions as a calcium regulator of release probability. Nature 410: 41-49, 2001.

11. Brose N, Petrenko AG, Südhof TC and Jahn R: Synaptotagmin: A calcium sensor on the synaptic vesicle surface. Science 256: 1021-1025, 1992. 
12. Sutton RB, Davletov BA, Berghuis AM, Sudhof TC and Sprang SR: Structure of the first C2 domain of synaptotagmin I: A novel Ca2+/phospholipid-binding fold. Cell 80: 929-938, 1995.

13. Perin MS, Fried VA, Mignery GA, Jahn R and Südhof TC: Phospholipid binding by a synaptic vesicle protein homologous to the regulatory region of protein kinase C. Nature 345: 260-263, 1990.

14. Fukuda M and Mikoshiba K: Characterization of KIAA1427 protein as an atypical synaptotagmin (Syt XIII). Biochem J 354: 249-257, 2001

15. Von CP and Südhof TC: Synaptotagmin 13: Structure and expression of a novel synaptotagmin. Eur J Cell Biol 80: 41-47, 2001.

16. Rickman C, Craxton M, Osborne S and Davletov B: Comparative analysis of tandem $\mathrm{C} 2$ domains from the mammalian synaptotagmin family. Biochem J 378: 681-686, 2004.

17. Grønborg M, Kristiansen TZ, Iwahori A, Chang R, Reddy R, Sato N, Molina H, Jensen ON, Hruban RH, Goggins MG, et al: Biomarker discovery from pancreatic cancer secretome using a differential proteomic approach. Mol Cell Proteomics 5: 157-171, 2006.

18. Jahn JE and Coleman WB: Re-expression of tumorigenicity after attenuation of human synaptotagmin 13 in a suppressed microcell hybrid cell line. Int J Oncol 32: 441-449, 2008.

19. Livak KJ and Schmittgen TD: Analysis of relative gene expression data using real-time quantitative PCR and the 2(-Delta Delta C(T)) method. Methods 25: 402-408, 2001.

20. László L: Predictive and prognostic factors in the complex treatment of patients with colorectal cancer. Magy Onkol 54: 383-394, 2010

21. Kulendran M, Stebbing JF, Marks CG and Rockall TA: Predictive and prognostic factors in colorectal cancer: A personalized approach. Cancers (Basel) 3: 1622-1638, 2011.

22. Chen TH, Chang SW, Huang CC, Wang KL, Yeh KT, Liu CN Lee $\mathrm{H}$, Lin $\mathrm{CC}$ and Cheng YW: The prognostic significance of APC gene mutation and miR-21 expression in advanced-stage colorectal cancer. Colorectal Dis 15: 1367-1374, 2013.

23. Falchook GS and Kurzrock R: VEGF and dual-EGFR inhibition in colorectal cancer. Cell Cycle 14: 1129-1130, 2015.

24. Xiao J, Lv D, Zhou J, Bei Y, Chen T, Hu M, Zhou Q, Fu S, and Huang Q: Therapeutic inhibition of miR-4260 suppresses colorectal cancer via targeting MCC and SMAD4. Theranostics 7: 1901-1913, 2017.

25. Koga Y, Yasunaga M, Takahashi A, Kuroda J, Moriya Y, Akasu T, Fujita S, Yamamoto S, Baba H, and Matsumura Y: MicroRNA expression profiling of exfoliated colonocytes isolated from feces for colorectal cancer screening. Cancer Prev Res (Phila) 3 : $1435-1442,2010$

26. Huang Z, Huang DS, Ni S, Peng Z, Sheng W and Du X: Plasma microRNAs are promising novel biomarkers for early detection of colorectal cancer. Int J Cancer 127: 118-126, 2010.

27. Li D, Yan D, Tang H, Zhou C, Fan J, Li S, Wang X, Xia J, Huang F, Qiu G and Peng Z: IMP3 is a novel prognostic marker that correlates with colon cancer progression and pathogenesis Ann Surg Oncol 16: 3499-3506, 2009.
28. Lin L, Zhang J, Wang Y, Ju W, Ma Y, Li L and Chen L: Insulin-like growth factor-II mRNA-binding protein 3 predicts a poor prognosis for colorectal adenocarcinoma. Oncol Lett 6: 740-744, 2013.

29. Johnson CP: Emerging functional differences between the synaptotagmin and ferlin calcium sensor families. Biochemistry 56 6413-6417, 2017.

30. Mizuta M, Inagaki N, Nemoto Y, Matsukura S, Takahashi M and Seino S: Synaptotagmin III is a novel isoform of rat synaptotagmin expressed in endocrine and neuronal cells. J Biol Chem 269: 11675-11678, 1994.

31. Grise F, Taib N, Monterrat C, Lagrée V and Lang J: Distinct roles of the $\mathrm{C}(2) \mathrm{A}$ and the $\mathrm{C} 2 \mathrm{~B}$ domain of the vesicular $\mathrm{Ca} 2^{+}$ sensor synaptotagmin 9 in endocrine beta-cells. Biochem J 403 . 483-492, 2007.

32. Andersson SA,Olsson AH,Esguerra JL, Heimann E, Ladenvall C, Edlund A, Salehi A, Taneera J, Degerman E, Groop L, et al: Reduced insulin secretion correlates with decreased expression of exocytotic genes in pancreatic islets from patients with type 2 diabetes. Mol Cell Endocrinol 364: 36-45, 2012.

33. Sreenath AS, Kumar KR, Reddy GV, Sreedevi B, Praveen D, Monika S, Sudha S, Reddy MG and Reddanna P: Evidence for the association of synaptotagmin with glutathione S-transferases: Implications for a novel function in human breast cancer. Clin Biochem 38: 436-443, 2005.

34. Thierry-Mieg D and Thierry-Mieg J: AceView: A comprehensive cDNA-supported gene and transcripts annotation. Genome Biol 7 (Suppl 1): S12, 2006.

35. Han S, Hong S, Lee D, Lee MH, Choi JS, Koh MJ, Sun W, Kim H and Lee HW: Altered expression of synaptotagmin 13 mRNA in adult mouse brain after contextual fear conditioning. Biochem Biophys Res Commun 425: 880-885, 2012.

36. Keck KJ, Breheny P, Braun TA, Darbro B, Li G, Dillon JS, Bellizzi AM, O'Dorisio TM and Howe JR: Changes in gene expression in small bowel neuroendocrine tumors associated with progression to metastases. Surgery 163: 232-239, 2018.

37. Jahn JE, Best DH and Coleman WB: Exogenous expression of synaptotagmin XIII suppresses the neoplastic phenotype of a rat liver tumor cell line through molecular pathways related to mesenchymal to epithelial transition. Exp Mol Pathol 89: 209-216, 2010.

38. Zhu H, Wu TC, Chen WQ, Zhou LJ, Wu Y, Zeng L and Pei HP Screening for differentially expressed genes between left- and right-sided colon carcinoma by microarray analysis. Oncol Lett 6: 353-358, 2013.

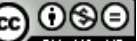

This work is licensed under a Creative Commons Attribution-NonCommercial-NoDerivatives 4.0 International (CC BY-NC-ND 4.0) License. 